\title{
PASSIVE PROTECTION OF LAMBS AGAINST EXPERIMENTAL ENTERIC COLIBACILLOSIS BY COLOSTRAL TRANSFER OF ANTIBODIES FROM K99-VACCINATED EWES
}

\author{
W. J. SojKa, C. Wray and J. A. Morris \\ Central Veterinary Laboratory, Weybridge, Surrey KT15 3NB
}

Colibacillosis is an important cause of mortality in lambs (Sojka, 1974). Two forms of the condition are recognised: a bacteriaemic form in lambs 2-3 weeks old caused by invasive strains of Escherichia coli, and neonatal coliform diarrhoea that affects lambs 2-8 days old (Sojka, 1971). In neonatal coliform diarrhoea, enteropathogenic strains of $E$. coli (EPEC) colonise the small intestine and produce an enterotoxin that causes diarrhoea. Strains that are enteropathogenic for lambs can also produce diarrhoea in susceptible calves and vice versa (Acres et al., 1975, Smith and Halls, 1967). Most of these "calf-lamb" EPEC strains possess a common surface antigen, K99 (Sojka, unpublished results, cited by Smith and Linggood, 1972; Ørskov et al., 1975). This plasmid-controlled (Smith and Linggood, 1972), pilus-like antigen (Burrows, Sellwood and Gibbons, 1976; Isaacson, 1977) appears to be a glycoprotein with a terminal $\alpha$-linked $\mathrm{N}$-acetylgalactosamine moiety and an adjacent $\alpha$-linked galactose moiety (Morris, Stevens and Sojka, 1977). It enables the organism to adhere to the intestinal epithelium and colonise the small intestine; this is essential before an EPEC strain can produce diarrhoea (Smith and Linggood, 1972). The few reports on the control of colibacillosis in lambs are confined to the prophylaxis of the systemic form of the disease (Sojka, 1974). The present study was undertaken to determine the feasibility of protecting newborn lambs against experimental enteric colibacillosis by vaccinating the dam with partially purified cell-free K99 antigen.

\section{MATERIALS AND METHODS}

Vaccine preparation. The cell-free K99 antigen was isolated and partially purified by the method described by Morris et al. (1977) from the K99 reference strain of $E$. coli, strain B41 (O101:K99:NM) (Ørskov et al., 1975). The first dose of vaccine contained protein $4 \mathrm{mg}$ per ml (Lowry et al., 1951) in Freund's incomplete adjuvant and the second dose contained

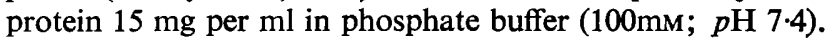

Challenge strains of E. coli. The enteropathogenic characteristics of E. coli strain B44, originally isolated from a fatal outbreak of enteric colibacillosis in calves, are well documented (Smith and Halls, 1967; Bywater, 1970, 1972; Smith and Linggood, 1972; Myers et al., 1973; Newman et al., 1973). Two forms of this strain were used as challenge doses:

Received 21 Nov. 1977; revised version accepted 4 Apr. 1978.

J. MED. MICROBIOL. -VOL. 11 (1978) 
(i) the mucoid form (O9:K30(A),K99:NM), and (ii) a non-mucoid variant (O9:K99:NM) that lacks the $\mathrm{K} 30$ antigen. Both strains produced a heat-stable enterotoxin when tested by the infant mouse test (Giannella, 1976).

Cultures of $E$. coli strains were maintained on Dorset egg slopes.

Preparation of challenge doses. The strains were plated on 5\% sheep-blood agar; after overnight incubation at $37^{\circ} \mathrm{C}$ a portion of an isolated colony was tested by slide agglutination with drops of OK B44 (O9:K30,K99) antiserum and absorbed K99 antiserum. The mucoid form of strain B44 was agglutinated only with OK B44 antiserum and gave a strong " doughy " type of $\mathrm{K}$ reaction; the non-mucoid variant reacted with both antisera and gave a finer agglutination. Each challenge strain was seeded in a Roux flask of sheep blood agar and after overnight incubation at $37^{\circ} \mathrm{C}$ the growth was harvested in $10 \mathrm{ml}$ of sterile physiological saline $(0.85 \% \mathrm{NaCl}) ; 7 \mathrm{ml}$ of the suspension was added to $43 \mathrm{ml}$ of warm cows' milk in a bottle and fed to lambs within 5-10 min. The number of organisms present in the challenge dose was estimated by the Miles, Misra and Irwin (1938) method. The challenge dose of the mucoid form varied from $7 \times 10^{10}-2.2 \times 10^{11}$ organisms, and that of the non-mucoid variant from $7.4 \times 10^{10}-1.8 \times 10^{11}$ organisms.

Preparation of antisera. OK B44 and OK B117 antisera were prepared in rabbits by the method of Sojka (1965). Absorbed K99 antiserum was prepared by absorbing OK B117 (O8:K85a, b, K99) antiserum with live suspensions of $E$. coli strains E68 II (O141:K85a, b) and $\mathrm{G} 7(\mathrm{O} 8: \mathrm{K} 87, \mathrm{~K} 88 \mathrm{a}, \mathrm{b})$.

Pregnant ewes. Fifteen Dorset Horn ewes at various stages of pregnancy were housed separately and examined daily. After lambing the dam and its offspring were kept together to ensure the uptake of colostrum by the lambs. The ewes were divided into two groups. Group 1 consisted of 11 ewes vaccinated by the intramammary route with $2 \mathrm{ml}$ of the first vaccine; 23 days later, $2 \mathrm{ml}$ of the second vaccine was administered subcutaneously. The time of vaccination varied from 33 to 64 days before lambing and no adverse reactions were observed. Group 2 consisted of 4 ewes given intramammary injections of $2 \mathrm{ml}$ of saline in Freund's incomplete adjuvant; 23 days later $2 \mathrm{ml}$ of saline were injected subcutaneously.

Lambs. Twenty-eight lambs that had been suckled by their dams (the ewes from groups 1 and 2) shortly after birth were examined clinically, and a serum sample and faecal swab were taken. They were then dosed orally with $E$. coli B44 within 4-21 h of birth; half of them were given the mucoid strain and the other half were given the non-mucoid variant. For 3 days after challenge the lambs were examined six times a day and thereafter twice daily. Rectal swabs were taken daily until the termination of the experiments; this varied from 1-22 days after challenge.

Rectal swabs from lambs were plated directly on to MacConkey agar. After overnight incubation at $37^{\circ} \mathrm{C}$ colonies of $E$. coli were tested by the slide agglutination method with OK B44 and absorbed $\mathrm{K} 99$ antisera for the presence of the challenge organism. The number of colonies tested varied from 1-10 depending on the number of colonies resembling the challenge strain present on the culture plate.

Necropsy specimen. At chosen times (1-17 days after challenge) 14 lambs were killed by intravenous injection of phenobarbitone. Total $E$. coli counts on the contents from the anterior, middle and posterior small intestine and the colon were made on MacConkey agar by the Smith and Crabb (1961) modification of the technique of Miles et al. (1938). Cultures from the liver were also made on 5\% sheep blood agar. Colonies from the MacConkey agar cultures of intestinal contents were examined for the presence of the challenge organisms by slide agglutination tests with OK B44 and absorbed K99 antisera.

Assay of antibodies to the K99 antigen. Samples of colostrum and sera from the ewes and the lambs were assayed for antibodies to $\mathrm{K} 99$ antigen by an indirect haemagglutination (IHA) test (Wray, Morris and Sojka, 1975), with cell-free K99 antigen adsorbed on to tanned sheep RBC. Microtitre trays were incubated at $37^{\circ} \mathrm{C}$ and examined after $2 \mathrm{~h}$.

Colostral samples of approximately $20 \mathrm{ml}$ were collected from individual glands shortly after lambing; the whey was separated (Logan and Penhale, 1971) and stored at $-20^{\circ} \mathrm{C}$. The blood samples were collected from pregnant ewes before the first vaccination and from lambs just before challenge; the serum was stored at $-20^{\circ} \mathrm{C}$. 


\section{RESULTS}

\section{Pre-challenge assessment}

Assay of antibodies to K99 antigen. The antibody titres to K99 antigen in the colostrum of the group 1 (vaccinated) dams were 512-8192 and the titres in the serum of their lambs were 128-1024; this indicates that all the lambs were suckled by their dams and had absorbed antibodies before being challenged. K99 antibodies were not detected in dams before vaccination.

Antibodies to K99 antigen were not detected either in colostrum from group 2 (control) dams or in undiluted serum from their lambs.

Bacteriological examination of faeces. Neither form of the challenge strain B44 was detected in the faeces of lambs before oral administration of the challenge dose.

\section{Results obtained with lambs challenged with the mucoid form of strain B44}

Lambs from group 1 (vaccinated) ewes. The challenge strain was excreted in the faeces for 3-9 days but was detected in large numbers $(>10$ colonies per culture plate) for only 1 day after challenge. One of the 10 lambs had loose faeces that persisted for 1 day after challenge (table). In the three lambs that were killed, $10^{2}-10^{4}$ organisms of the challenge strain were detected per gram of small intestinal contents and no lesions were observed. All lambs were healthy at the termination of the experiment 7-19 days after challenge.

Lambs from group 2 (control) ewes. All four lambs born to the nonvaccinated ewes and suckled by them developed severe watery diarrhoea within $6 \mathrm{~h}$ of challenge (table). One day after challenge two lambs were unable to stand, became comatose and were killed in extremis; at necropsy large numbers $\left(10^{9}\right.$ organisms per $\left.\mathrm{g}\right)$ of the challenge organism were found in the contents of the small intestine and colon. The other two lambs became dehydrated, weak and unable to stand; one of them died 5 days after the challenge; at necropsy

TABLE

Results obtained when lambs from vaccinated and unvaccinated dams were challenged with the mucoid and non-mucoid forms of E. coli B44

\begin{tabular}{|c|c|c|c|c|}
\hline \multirow{3}{*}{ Clinical effect } & \multicolumn{4}{|c|}{ Number* of affected animals produced by giving (by mouth) } \\
\hline & \multicolumn{2}{|c|}{$\begin{array}{l}\text { the mucoid }(\mathrm{O} 9: \mathrm{K} 30, \mathrm{~K} 99: \mathrm{NM}) \\
\text { form of strain B44 to }\end{array}$} & \multicolumn{2}{|c|}{$\begin{array}{l}\text { the non-mucoid }(09: \mathrm{K} 99: \mathrm{NM}) \\
\text { form of strain B44 to }\end{array}$} \\
\hline & $\begin{array}{c}\text { lambs of } \\
\text { vaccinated } \\
\text { dams }\end{array}$ & $\begin{array}{l}\text { lambs (controls) } \\
\text { of unvaccinated } \\
\text { dams }\end{array}$ & $\begin{array}{c}\text { lambs of } \\
\text { vaccinated } \\
\text { dams }\end{array}$ & $\begin{array}{c}\text { lambs (controls) } \\
\text { of unvaccinated } \\
\text { dams }\end{array}$ \\
\hline $\begin{array}{l}\text { Death } \\
\text { Severe diarrhoea } \\
\text { Loose faeces }\end{array}$ & $\begin{array}{l}0 / 10 \\
0 / 10 \\
1 / 10\end{array}$ & $\begin{array}{l}3 / 4 \dagger \\
4 / 4 \\
\ldots\end{array}$ & $\begin{array}{l}0 / 10 \\
0 / 10 \\
0 / 10\end{array}$ & $\begin{array}{l}0 / 4 \\
0 / 4 \\
2 / 4\end{array}$ \\
\hline
\end{tabular}

${ }^{*}$ Number affected/number in group. $†$ Two lambs killed in extremis. 
the challenge organism was isolated in large numbers $\left(8.5 \times 10^{8}\right.$ organisms per g) from the contents of the posterior small intestine. At necropsy, the three dead lambs showed signs of dehydration; clotted milk was found in the abomasum and there was hyperaemia and reddening of the mucosa of the small intestine; the posterior small intestine and large intestine were distended with fluid and the associated lymph nodes were oedematous and swollen. The other lamb recovered on the 5th day after challenge and excreted the challenge organism for 8 days.

\section{Results obtained with lambs challenged with the non-mucoid variant of strain B44}

Lambs from group 1 (vaccinated) ewes. None of the 10 lambs showed signs of intestinal disturbance after challenge (table). One lamb developed rapid, shallow breathing immediately after challenge and was recumbent, but it recovered the following day. All lambs excreted the challenge organism, for 1-5 days after challenge; the number of detectable colonies of the challenge organism varied from 1-10 per culture plate. The challenge organism, however, was not detected in the intestinal contents of five of the six animals killed 2-17 days after challenge; $10^{5}$ organisms per $\mathrm{g}$ of small intestinal contents were found in one lamb killed on the 2nd day after challenge.

Lambs from group 2 (control) ewes. Two of the four lambs born to unvaccinated dams had loose faeces for 1 day after the oral challenge (table). They were killed 2 days after challenge and $1.3 \times 10^{3}-1 \times 10^{6}$ challenge organisms per gram of small intestinal contents were found. The other two lambs were healthy; one of them was killed 1 day after challenge and $10^{5}$ challenge organism per $\mathrm{g}$ of small intestinal contents were present. The other lamb remained healthy until the experiment was terminated 20 days after challenge. The challenge organism could not be detected in the faeces beyond $24 \mathrm{~h}$ after the challenge dose.

\section{Discussion}

Most outbreaks of neonatal enteric colibacillosis caused by the "calflamb " EPEC strains occur during the 1st week of life in lambs (Sojka, 1971) and within $48 \mathrm{~h}$ of birth in calves (Gay, McKay and Barnum, 1964). The infective organism is confined to the intestinal tract and, therefore, it is likely that the presence of a specific antibody in the intestinal lumen will protect the neonate from this form of the disease. Newborn calves and lambs are devoid of local antibody, but are capable of developing it soon after birth; thus colostral antibody may furnish passive protection to the gastro-intestinal tract until the local antibody system becomes established.

Myers et al. (1973) and Newman et al. (1973) showed that immunisation of the dam stimulated the production of protective factors that were transferred to the neonate in the colostrum; calves born to dams immunised with $E$. coli vaccine were protected against experimental enteric colibacillosis. The present investigation showed that vaccination of pregnant ewes with cell-free K99 antigen protected the offspring from experimental colibacillosis when they were 
challenged with EPEC strain B44 (table). Moreover, the challenge organisms were detected in only small numbers in the faeces of lambs from vaccinated dams, and for only a short time after challenge. Small numbers of challenge organisms were detected in the small intestinal contents of killed lambs from the group 1 (vaccinated) ewes; in only one animal was the number of challenge organisms as high as $10^{5}$ per $g$ of contents. This finding differs from that of Myers et al. (1973) who found that the protective factor in colostrum from vaccinated cows did not eliminate the challenge organism from the lower intestinal tract of their calves. Smith (1971) found $\leqslant 10^{5} \mathrm{E}$. coli per $\mathrm{g}$ of contents in the upper small intestine of healthy calves. Counts of $<10^{7} E$. coli per $g$ of small intestinal contents were considered to be the normal range by Morin, Larivière and Lallier (1976). Acres et al. (1975) reported that a very large number of $E$. coli $\left(2 \times 10^{10}\right.$ organisms per $\left.\mathrm{g}\right)$ was present in the small intestinal contents of unvaccinated lambs that developed diarrhoea after oral challenge with $E$. coli B44. Similarly, during the present investigation, large numbers $\left(c .10^{9}\right.$ organisms per $\left.\mathrm{g}\right)$ of the challenge organism were detected at necropsy in the small intestinal contents of lambs that were born to unvaccinated ewes and developed severe diarrhoea after challenge with the mucoid form of strain B44.

Isaacson, Nagy and Moon (1977) reported that both the capsule and the pili of some porcine EPEC strains were involved in colonisation of the pig intestine. Thus the non-capsulate but pilate mutant of one of the porcine EPEC strains failed to colonise pigs' small intestines. The results of the present investigation suggest that the mucoid-polysaccharide $\mathrm{K}$ antigen may contribute to the virulence of the "calf-lamb" EPEC strain. None of the four control lambs challenged with the non-mucoid variant of strain B44 developed severe diarrhoea and it is probable that this variant $(09: \mathrm{K} 99: \mathrm{NM})$ may be less pathogenic than the mucoid form of strain B44 (O9:K30,K99:NM). Both forms of the challenge strain B44 produced heat-stable enterotoxin and both possessed the K99 antigen, the only difference between the two being the absence of the capsular polysaccharide K30(A) antigen from the non-mucoid variant. The precise role that the capsule plays in colonisation is uncertain. However, vaccination of dams with partially purified cell-free K99-antigen preparation afforded passive protection, via colostrum, to lambs against enteric colibacillosis when they were challenged orally with the mucoid form of B44 that produced severe diarrhoea in control lambs. Because the K99 vaccine was prepared from the heterologous $E$. coli strain B41 (O101:K99:NM), it is probable that antibody against K99 antigen alone was the protective factor. This illustrates the importance of the antigen in the enteropathogenicity of the "calf-lamb" EPEC strains.

\section{SUMMARY}

Pregnant ewes were vaccinated with partially purified, cell-free K99 antigen isolated from an enteropathogenic strain of Escherichia coli, strain B41 (O101:K99:NM), to induce passive immunity via the colostrum in their off- 
spring against an oral challenge with heterologous "calf-lamb" enteropathogenic strains of $E$. coli B44. After sucking their dams, lambs were dosed orally with $7 \times 10^{10}-2 \cdot 2 \times 10^{11}$ organisms within $4-21 \mathrm{~h}$ of birth. One group of 10 lambs was dosed with cultures of the mucoid (O9:K30(A),K99:NM) form of strain B44 and another group of 10lambs with the non-mucoid (O9:K99:NM) form; two groups of four control lambs from unvaccinated dams were similarly challenged. All four control lambs challenged with mucoid B44, but none of 10 lambs from vaccinated dams, developed severe, watery diarrhoea. In the group of lambs challenged with the non-mucoid form of strain B44, loose faeces were detected in only two of the four control lambs and in none of the lambs from vaccinated dams. This suggests that the polysaccharide $\mathrm{K}$ antigen may contribute to the virulence of "calf-lamb" enteropathogenic strains that possess the K99 antigen. However, lambs passively immunised with colostrum from dams vaccinated with K99 antigen alone were protected against the production of enteric colibacillosis by oral challenge with EPEC strain B44.

\section{REFERENCES}

ACres, S. D., LAING, C. J., SAunders, J. R. AND RadostrTs, O. M. $1975 . \quad$ Acute undifferentiated neonatal diarrhea in beef calves. I. Occurrence and distribution of infectious agents. Can. J. comp. Med., 39, 116.

BurRows, M. R., Sellwood, R. AND GibBons, R. A. 1976. Haemagglutinating and adhesive properties associated with the K99 antigen of bovine strains of Escherichia coli. J. gen. Microbiol., 96, 269.

BYWATER, R. J. 1970. Some effects of Escherichia coli enterotoxin on net fluid, glucose, and electrolyte transfer in calf small intestine. J. comp. Path., 80, 565.

BYwATER, R. J. 1972. Dialysis and ultrafiltration of a heat-stable enterotoxin from Escherichia coli. J. med. Microbiol., 5, 337.

Gay, C. C., McKay, K. A. AND Barnum, D. A. 1964. Studies on colibacillosis of calves. III. The experimental reproduction of colibacillosis. Can. vet. J., 5, 314.

GlanNella, R. A. 1976. Suckling mouse test model for detection of heat-stable Escherichia coli enterotoxin: characteristics of the model. Infect. Immun., 14, 95.

IsAACSON, R. E. 1977. K99 surface antigen of Escherichia coli: purification and partial characterization. Infect. Immun., 15, 272.

IsAaCsON, R. E., NAGY, B. AND MoON, H. W. 1977. Colonization of porcine small intestine by Escherichia coli: colonization and adhesion factors of pig enteropathogens that lack K88. J. infect. Dis., 135, 531.

Logan, E. F. AND Penhale, W. J. 1971. Studies on the immunity of the calf to colibacillosis. I. The influence of colostral whey and immunoglobulin fractions on experimental colisepticaemia. Vet. Rec., 88, 222.

Lowry, O. H., Rosenbrough, N. J., Farr, A. L. AND Randall, R. J. 1951. Protein measurement with Folin phenol reagent. J. biol. Chem., 193, 265.

Miles, A. A., MisRA, S. S. AND IRWIN, J. O. 1938. The estimation of the bactericidal power of the blood. J. Hyg., Camb., 38, 732.

Morin, M., Larivière, S. AND Lallifi, R. 1976. Pathological and microbiological observations made on spontaneous cases of acute neonatal calf diarrhea. Can.J. comp. Med., 40, 228.

Morris, J. A., Stevens, A. E. AND SojKA, W. J. 1977. Preliminary characterization of cellfree K99 antigen isolated from Escherichia coli B41. J. gen. Microbiol., 99, 353.

Myers, L. L., Newman, F. S., Wilson, R. A. and Catlin, J. E. 1973. Passive immunization of calves against experimentally induced enteric colibacillosis by vaccination of dams. Am. J. vet. Res., 34, 29. 
Newman, F. S., Myers, L. L., Firehammer, B. D. and Catlin, J. E. 1973. Prevention of experimentally induced enteric colibacillosis in newborn calves. Infect. Immun., 8, 540.

ØrSkov, I., ØRSKov, F., Smith, H. Williams AND SojKa, W. J. 1975. The establishment of K99, a thermolabile, transmissible Escherichia coli $\mathrm{K}$ antigen, previously called " Kco," possessed by calf and lamb enteropathogenic strains. Acta. path. microbiol. scand., Sect. B, 83, 31 .

Smith, H. WiLliams 1971. The bacteriology of the alimentary tract of domestic animals suffering from Escherichia coli infection. Ann. N.Y. Acad. Sci., 176, 110.

Smith, H. Williams AND CRABb, W. E. 1961. The faecal bacterial flora of animals and man: its development in the young. J. Path. Bact., 82, 53.

Smith, H. Williams and Halls, S. 1967. Observations by the ligated intestinal segment and oral inoculation methods on Escherichia coli infections in pigs, calves, lambs and rabbits. J. Path. Bact., 93, 499.

Smith, H. Williams AND LiNGGOOD, M. A. 1972. Further observations on Escherichia coli enterotoxins with particular regard to those produced by atypical piglet strains and by calf and lamb strains: the transmissible nature of these enterotoxins and of a $\mathrm{K}$ antigen possessed by calf and lamb strains. J. med. Microbiol., 5, 243.

SoJKA, W. J. 1965. Escherichia coli in domestic animals and poultry. Farnham Royal, England.

SoJkA, W. J. 1971. Enteric diseases in new born piglets, calves and lambs due to Escherichia coli infection. Vet. Bull., 41, 509.

SoJkA, W. J. 1974. Colibacillosis en los corderos. Trib. vét., 4, No. 170, p. 3; No. 171, p. 3 ; No. 172 , p. 3.

WraY, C., Morris, J. A. AND SoJKA, W. J. 1975. A comparison of indirect haemagglutination tests and serum agglutination tests for the serological diagnosis of Salmonella dublin infection in cattle. Br. vet.J., 131, 727. 